\title{
BMJ Global Health Ten-year impacts of China's rural health scheme: lessons for universal health coverage
}

\author{
Yaoguang Zhang, ${ }^{1}$ Di Dong (D) ${ }^{2}$ Ling Xu, ${ }^{3}$ Zhiwen Miao, ${ }^{1}$ Wenhui Mao (D) , ${ }^{4}$ \\ Frank Sloan, ${ }^{5}$ Shenglan Tang ${ }^{4}$
}

To cite: Zhang Y, Dong D, Xu L, et al. Ten-year impacts of China's rural health scheme: lessons for universal health coverage. BMJ Global Health 2021;6:e03714. doi:10.1136/ bmjgh-2020-003714

\section{Handling editor Lei Si}

- Additional material is published online only. To view please visit the journal online (http://dx.doi.org/10.1136/ bmjgh-2020-003714)

YZ and DD contributed equally.

$\mathrm{YZ}$ and DD are joint first authors.

Received 13 August 2020

Revised 20 January 2021

Accepted 29 January 2021

\section{Check for updates}

\section{Author(s) (or their} employer(s)) 2021. Re-use permitted under CC BY-NC. No commercial re-use. See rights and permissions. Published by BMJ.

For numbered affiliations see end of article.

Correspondence to Dr Shenglan Tang; shenglan.tang@duke.edu

\section{ABSTRACT}

China has made profound progress in advancing universal health coverage (UHC) over the past two decades. New Cooperative Medical Scheme (NCMS) was initiated in 2003 to provide health insurance coverage to rural population. Its benefit packages and cost-sharing mechanism have changed significantly over time. This study aims to assess the impact of changing NCMS policies on NCMS enrollees' service utilisation, medical financial burden and equity between 2003 and 2013. Data are from China National Health Services Survey (NHSS) which is conducted every 5 years. We used the subsample of NHSS that were enrolled in NCMS in 2003, 2008 and 2013. From 2003 to 2013, we found increased service utilisation and an elimination of inequity in service utilisation with respect to income. Contradicting prior findings of increasing financial burden after the NCMS implementation, we identified significant protective effect of NCMS against financial risks, and a reduction in percentage of households with high medical expenditure in the middle-income and high-income quintiles. The rural residents from the lowincome groups have high financial risk, therefore, should be the priority target for future reforms. In pursuit of UHC globally, many countries struggle to provide good coverage to the disadvantaged rural population and balance between the competing priorities of various UHC dimensions. Our trend analysis revealed China's two-stage approach with NCMS reform that first focused on expanding population coverage, then on service coverage and financial risk protection. This path could potentially be replicated in other middle-income and low-income countries to pave the way for UHC.

\section{INTRODUCTION}

China has made significant progress in establishing several government supported health insurance schemes to provide universal health coverage (UHC) for its population. Three insurance schemes have played critical roles in covering different groups of population. The Urban Employees' Basic Medical Insurance (UEBMI) was established in 1999, covering the employees (and retirees) in urban regions. In 2003, the New Cooperative Medical Schemes (NCMS) was established to provide financial risk protections for rural residents, and in 2007, Urban

\section{Key questions}

What is already known?

- There was abundant evidence about the improved use of inpatient services among rural Chinese after the implementation of New Cooperative Medical Scheme (NCMS) since 2003, however, impact of NCMS on outpatient service use, financial protection and equity show mixed evidence.

\section{What are the new findings?}

- From 2003 to 2013, we found increased service utilisation and an elimination of inequity in service utilisation with respect to income. Contradicting some prior findings of increasing financial burden after the NCMS implementation, we identified significant protective effects of NCMS against financial risks and catastrophic health expenditures in all income groups.

What do the new findings imply?

- China's two-stage approach with NCMS reform has demonstrated a viable path to gradually expand coverage to the disadvantaged rural population: first focusing on expanding population enrolment, inpatient coverage and equity, then emphasising on outpatient coverage and financial risk protection. This could potentially be replicated in other middle-income and low-income countries to pave the way for Universal Health Coverage.

Residents' Basic Medical Insurance (URBMI) was established to cover the remaining residents in urban areas that were not covered by UEBMI. Among the three schemes, NCMS has covered the largest number of populations in China, and has made policy innovations and provided enormous experiences in providing UHC, especially for residents in informal sector.

The NCMS was first piloted in 4 provinces in 2003, and then expanded gradually, aiming to improve the access of rural residents to healthcare and to reduce financial risks, especially for catastrophic medical expenditures. Since its establishment, NCMS financing level has 
increased more than 20 folds $^{1}$ (from US $\$ 4.6$ per enrollee in 2003 to US $\$ 90.1$ in 2016), with significant expansion in benefit packages. Despite the voluntary enrolment mechanism, its enrolment rate has been over $91.5 \%$ nationwide since 2008. ${ }^{12}$ The policy framework and fund pooling of NCMS are decentralised and the level of decentralisation varies across provinces. ${ }^{3}$ The financing contribution of NCMS is composed of individual premium and government subsidies. While the central government defines the minimal levels for the premium and government subsidies, local governments are required to subsidise the most of the premium. ${ }^{12}$ Across the country, NCMS benefit packages and cost-sharing mechanism have been significantly changed over the past two decades. When first started, the reimbursement rate for inpatient services was around $40 \%$, and varied by region and level of healthcare facilities, with more generous reimbursement rate for expenses at lower level health facilities. ${ }^{4}$ In 2010, NCMS started to cover outpatient services ${ }^{5}$ and a supplementary programme covering 22 catastrophic diseases with reimbursement rates higher than $70 \%$ was introduced; and in 2012, the catastrophic disease insurance was expanded from 22 diseases to cover at least $50 \%$ of out-of-pocket (OOP) inpatient expenses over deductible that were eligible for reimbursement regardless of diseases. ${ }^{6}$ In 2013, the average reimbursement rate for eligible outpatient and inpatient expenses were above $50 \%$ and $75 \% .^{6}$ (see box 1 for policy context of NCMS).

Two key objectives of NCMS are to promote the utilisation of health services among the rural population and provide financial protection against catastrophic expenditures for rural households. In addition, as one of the government schemes to achieve UHC, NCMS aims to benefit the whole rural population including the poor and vulnerable, and improving healthcare equity. Due to the cost-sharing design of NCMS, higher service utilisation may lead to higher OOP payment. Even small amount of OOP payment may be catastrophic to the poor households. Therefore, assessing the equity impact of NCMS on both service utilisation and financial protection is critical. There was abundant evidence about the improved access to and use of inpatient services after the implementation of NCMS. ${ }^{24} 7$ Evidence on the impact of NCMS on use of outpatient services was mixed. While some studies identified positive impact of NCMS on outpatient service utilisation, ${ }^{8}$ other studies did not find NCMS to be associated with increased outpatient use, ${ }^{79} 10$ with the possible explanation that NCMS policies focus mainly on inpatient coverage to prevent catastrophic health expenditure. ${ }^{9}$ In addition to methodological differences, the mixed results may also reflect regional variations in NCMS policies and heterogeneity across income and age groups. In terms of financial risk protection, most early evaluation studies have found little evidence on the effect of NCMS in reducing OOP expenditure and catastrophic expenditures, despite the improved coverage. ${ }^{2711}$ Two recent studies on NCMS in general or in specific disease areas also showed no evidence of reduced OOP expenditure. ${ }^{12} 13$
Box 1 Policy context of New Cooperative Medical Scheme (NCMS)

\section{Premium and revenue sources}

When first started in 2003, the annual premium was a flat-rate of $¥ 30$ (US\$4.6) per enrollee, among which the insured individual, central government, and local government each contributed $¥ 10$ (US $\$ 1.5){ }^{2}$ NCMS premium increased gradually each year, with most of the premium subsidised by the different levels of governments. In 2008, the average annual premium was $¥ 96$ (US\$13.9), among which $¥ 80$ (US\$11.6) was contributed by the government. In 2013, the premium averaged about $¥ 370$ (US\$59), with $¥ 280$ (us $\$ 44.4$ ) subsidised by the government. Recently, in 2016, the premium reached around $¥ 570$ (US\$90.1) ( $¥ 120$ from insured individual, and on average $¥ 420$ from central and local governments) nationwide.

More developed regions set higher premium and the major subsidy come from regional governments; whereas central government provides more subsidies to those less developed regions. For households living in poverty, the individual premium contributions are further subsidised by the local Civil Affairs Department.

\section{Risk pooling}

NCMS has two prominent features in risk pooling. ${ }^{3}$ First, the policy framework and fund pooling are decentralised, and the level of decentralisation varies across provinces, ranging from provincial-level to county-level management. The premium, sources of financing, benefit packages and cost-sharing mechanism are at the discretion of individual NCMS management offices, following general principles and guidelines set at national and provincial levels. This allows the NCMS policies to be aligned with regional budget constraints and medical needs. Second, NCMS enrolment was household-based in most regions (with the exception of rural residents already enrolled in the Urban Employee Basic Medical Insurance through employer), and all family members are required to enrol to reduce adverse selection.

\section{Benefits and reimbursements}

Across the country, NCMS benefit packages have been significantly expanded and cost-sharing mechanism has changed over the past decade. When first started, the reimbursement rate for inpatient services was around $40 \%$, and varied by region and level of healthcare facilities, with more generous reimbursement rate for expenses at lower level health facilities. ${ }^{4}$ In 2010, NCMS started to cover outpatient services ${ }^{5}$ and a supplementary programme covering 22 catastrophic diseases with reimbursement rates higher than $70 \%$ was introduced; and in 2012, the catastrophic disease insurance was expanded from 22 diseases to cover at least $50 \%$ of out-of-pocket inpatient expenses over deductible that were eligible for reimbursement regardless of diseases. ${ }^{6}$ In 2013 , the average reimbursement rate for eligible outpatient and inpatient expenses were above $50 \%$ and $75 \%{ }^{6}$. In order to alleviate patients overcrowding in big tertiary hospitals, lower reimbursement rate was provided in higher level health facilities. In order to further reduce the financial burden of low-income households (Dibao), Medical Financial Assistance funded by Ministry of Civil Affairs, the safety net program, helps to pay fully or a portion of the premium, and provides further subsidies on NCMS deductibles and copayments.

With the rapid expansion of population coverage and benefit package, and huge variations in NCMS policies, evidence gaps still exist, including how the utilisation of inpatient and outpatient services has changed over the past decade on a national level, and if NCMS improves 
equity in healthcare access and financial protection, and if it disproportionally favours the low-income groups. $^{2} 4711$ 14-16 After 15 years of experiences with NCMS, and in the context of a current reform to merge NCMS with the URBMI in an increasing number of provinces in China to reduce urban-rural disparity, it is critical to review the NCMS implementation experiences and impact of changing NCMS policies on NCMS enrollees' service utilisation, medical financial burden and equity between 2003 and 2013. This study aims to achieve four objectives: (1) to provide an assessment of the time trends in NCMS enrollees' service utilisation quantity, location and type, (2) to examine the impact of NCMS on medical financial burden since the start; (3) to investigate if NCMS has improved equity in health services with respect to income and (4) to identify the achievements in two distinct stages of NCMS reform and synthesise lessons on the progressive strategies. The unique pathway of China's NCMS expansion in the past 15 years could shed light on how to gradually move towards UHC in China and other middle-income and low-income countries, particularly among resource-constrained rural areas.

\section{METHODS \\ Data}

China National Health Services Survey

National Health Services Survey (NHSS) is one of the largest nationally representative cross-sectional household survey of Chinese residents' demographic and socioeconomic status, health insurance enrolment, health needs, health service access and utilisation, medical expenditures and health. NHSS is conducted every 5 years by the Center for Health Statistics and Information of China National Health and Family Planning Commission. The detailed methodology can be found elsewhere. ${ }^{1}$ Briefly, NHSS used a multistage sampling approach. The three levels of sampling units in rural areas are county, township and village. Despite the repeated crosssectional survey design, NHSS maintained good consistency in sample villages to improve comparability across the different waves. In the 2003 and 2008 waves, most sampled villages remained the same, and households were randomly sampled from these villages, and demographic and social economic characteristics were checked after sampling. Since 2013, some new sample county was added. The sampling methodology ensures good comparability across the waves, therefore the validity of time trend analysis.

In 2003, 2008 and 2013, the number of households sampled was 57 023, 56456 and 93613, respectively. All members in each household were surveyed by face-toface interviews with structured questionnaires, totaling 193 689, 177501 and 273688 residents were surveyed.

This study used the subsample of NHSS respondents that were enrolled in NCMS in 2003, 2008 and 2013, which accounts for $8.75 \%, 68.66 \%$ and $51.71 \%$ of NHSS total sample in the three waves, respectively. In 2003,
NCMS only started as pilot programmes in selected counties, therefore the number of NCMS enrollees was much smaller in this wave. Though NCMS pilot counties were not randomly selected, ${ }^{3}$ literature and our analysis show that rural residents who enrolled in NCMS were only slighter richer than those not enrolled, and there was no significant difference in their health status or other socioeconomic characteristics. ${ }^{9}$

\section{Definition and measurement of key variables}

Definition and calculation of key variables are summarised in online supplemental table 1 .

Measurement of demographic and socioeconomic indicators at individual level and household level

Health service utilisations are assessed on an indivudal level, whereas catastrophic medical expenditures are typically measured at household level. The study, therefore, adopted two sets of demographic and socioeconomic indicators. On individual levels, measurements include: individual age, gender and education. On household levels, characteristics consisted of: household size, highest education of household members, total and per capita household income, if a household has at least one member above 60 years old, if a household has at least one member below 5 years, and if at least one member in household has a chronic disease.

\section{Measurement and classification of income}

In NHSS, the household income in rural regions was defined as self-reported net household income, including income from farming, and formal and informal employment. To reduce the effects of household size, the per capita income was calculated as total household income over household size. The per capita household income for each individual was ranked, and classified into five quintiles.

\section{Measurements of service utilisation quantity and pattern}

The rural residents' health service utilisation was measured by outpatient service utilisation (visited outpatient clinic in the past 2 weeks) and inpatient service utilisation (hospitalised within the past year). Pattern of service utilisation was used as a structural approximate of service quality, as services provided at tertiary health institutions were perceived better in quality compared with the county-level and township-level facilities. Township-level health facilities were referred to as lower-level health facilities in this study.

\section{Measurements of financial risk and underlying determinants}

Three indicators were used to quantify medical financial risk and burden over time: (1) having a catastrophic medical expenditure (defined as annual OOP medical expenditure exceeding $40 \%$ of annual household income); (2) forgoing necessary hospital admissions (judged by physician) due to financial difficulties, and (3) early hospital discharge due to financial difficulties. The first indicator was assessed at household level as the financial resources are usually pooled within household, 
whereas the other two indicators were at individual level capturing the gap between medical needs and actual service utilisation due to financial difficulties. Income and medical expenditures have been adjusted for Consumer Price Index (CPI) using 2003 as reference level. The adjustment ratios for 2008 and 2013 were $114 \%$ and $134 \%$, respectively.

\section{Statistical analysis}

To reveal the time trends among different sub populations and equity impact of NCMS, results were stratified by income quintiles and age groups (No correlation was found between income quintiles and age groups). Statistical significance of results was examined using $\chi^{2}$ tests. Service utilisations were analysed at individual level as individual factors are likely to determine service utilisation. Financial burden was analysed at both individual and household levels due to the resource pooling among the members of the same households. The householdlevel indicator was: per cent of households with health OOP exceeding $40 \%$ of income; and the individual indiators used were: Did not get admitted when considered necessary by physicians, Forgone necessary admissions due to financial difficulties, and Early discharge due to financial difficulties.

To assess the equity impact of NCMS on health service utilisation, concentration curves were plotted. The concentration curve plots the cumulative percentage of the inpatient or outpatient service utilisation (y axis) against the cumulative percentage of the population, ranked by per capita income, beginning with the poorest and ending with the richest ( $\mathrm{x}$ axis). The concentration index $\mathrm{C}$ was computed using the following formula:

$$
\mathrm{C}=\left(\mathrm{p}_{1} \mathrm{~L}_{2}-\mathrm{p}_{2} \mathrm{~L}_{1}\right)+\left(\mathrm{p}_{2} \mathrm{~L}_{3}-\mathrm{p}_{3} \mathrm{~L}_{2}\right)+\ldots+\left(\mathrm{p}_{\mathrm{T}-1} \mathrm{~L}_{\mathrm{T}}-\mathrm{p}_{\mathrm{T}} \mathrm{L}_{\mathrm{T}-1}\right) \text {, }
$$

where $p$ is the cumulative percent of the sample ranked by per capita income, $\mathrm{L}(\mathrm{p})$ is the corresponding concentration curve ordinate and $\mathrm{T}$ is the number of income groups.

To further examine the time trends of high financial burden (having OOP medical cost exceeding $40 \%$ of annual household income) over time and to identify underlying determinants, three multi-variate logistic regression models were used by adding control variables in a stepwise manner. Catastrophic medical expenditure has many causes, including healthcare demand factors (such as household demographics and healthcare needs), income factors, actual health service utilisation, as well as other contextual factors (such as regional variation in medical practice and insurance policies). Model 1 only controlled for geographic region; Model 2 controlled for geographical region, household size, education, demographic structure (with child below 5 years old; with elderly person above 60 years old), health status (any member has chronic disease) and model 3 further controlled for inpatient service utilisation (any member used inpatient service) in addition to all other variables in model 2 . All variable definitions are detailed in online supplemental table 1 . We present model 3 as the main model in the manuscript and results for models 1 and 2 are provided in online supplemental table 2. In all models, within-county correlations were accounted for by using county cluster-robust standard errors for significant tests. All statistical analyses were conducted using STATA14.

\section{Patient and public involvement statement and ethical approval}

This study does not involve patients. The study also does not involve human participants. The study conducted secondary data analysis on the NHSS. NHSS received ethical approval from the National Statistics Bureau of China, and no individual identifiable data (name, address, phone number, etc) were collected.

\section{RESULTS \\ Sample characteristics, health needs and healthcare use in 2003, 2008 and 2013}

From 2003 to 2008 and 2011, demographics and health needs, socio-economic characteristics, and healthcare access changes significantly among NCMS enrollees (table 1). The average household size decreased significantly from 3.8 in 2003 to 3.0 in 2013, while percentage of households with at least one member over 60 years increased. In addition, more and more households had a member with chronic diseases $(36.4 \%$ in 2003 and $42.1 \%$ in 2013), implying the increasing healthcare needs. The percent of individuals completed higher education steadily increased, and the annual household income almost doubled from 2003 to 2013, with most of the increase occurring after 2008. On the health service supply side, access was improved, with $88.6 \%$ of households living within $20 \mathrm{~min}$ distance to the nearest health facility in 2013 compared with $84.1 \%$ in 2003 .

\section{Improved health service utilisation and decreasing medical financial burden on a national level from 2003 to 2013}

Percentage of individuals who had outpatient visits in the past 2 weeks before survey increased from 2003 to 2008 but decreased from 2008 to 2013 (table 2). In contrast, the percentage of residents hospitalised significantly increased over time, from $2.7 \%$ in 2003 to $5.7 \%$ in 2008, and to $7.7 \%$ in 2013 (table 2). Additionally, the location of inpatient care also changed. The proportion of admissions in lower-level health facilities (township health centres) increased from 2003 to 2008 but decreased from 2008 to 2013.

The concentration index for inpatient service utilisation has decreased significantly from 0.15 in 2003 to 0.02 in 2008 , then -0.02 in 2013 , showing that equality of inpatient service utilisation with respect to income have significantly improved over time. In contrast, there was no evidence of inequality of outpatient service utilisation with respect to income in the baseline of 2003, and the trend did not change significantly over time (concentration index 0.03 in 2003, 0.01 in 2008 and -0.26 in 2013). 
Table 1 Characteristics of surveyed households and individuals in 2003, 2008 and 2013

\begin{tabular}{|c|c|c|c|}
\hline & 2003 & 2008 & 2013 \\
\hline \multicolumn{4}{|l|}{ Households } \\
\hline $\mathrm{N}$ & $3807^{*}$ & 33958 & 43478 \\
\hline Average household size & 3.8 & 3.3 & 3.0 \\
\hline \multicolumn{4}{|l|}{ Highest education of all family members (\%) } \\
\hline None and primary & 41.8 & 34.2 & 33.5 \\
\hline Secondary & 56.7 & 63.6 & 61.5 \\
\hline College and above & 1.6 & 2.1 & 4.9 \\
\hline With member over age 60 years (\%) & 34.0 & 34.2 & 40.2 \\
\hline With member below 5 years (\%) & 16.2 & 16.4 & 16.3 \\
\hline Any member has chronic disease (\%) & 36.4 & 35.6 & 42.1 \\
\hline Any member use inpatient medical servicest(\%) & 7.4 & 13.2 & 17.6 \\
\hline$\%$ households living within 20 min distance from the nearest health facility (\%) & 84.1 & 84.6 & 88.6 \\
\hline Annual household income (US\$)‡ & 1336.5 & 2016.4 & 3495.3 \\
\hline Annual household out-of-pocket medical expenditure (US\$) & 97.7 & 181.0 & 308.2 \\
\hline \multicolumn{4}{|l|}{ Individuals } \\
\hline $\mathrm{N}$ (individual) & 16950 & 121870 & 141513 \\
\hline \multicolumn{4}{|l|}{ Gender } \\
\hline Male (\%) & 49.5 & 49.9 & 49.6 \\
\hline Age (mean) & 34.7 & 36.7 & 39.4 \\
\hline \multicolumn{4}{|l|}{ Education (\%) } \\
\hline None and primary & 64.4 & 51.4 & 47.5 \\
\hline Secondary & 35.0 & 47.7 & 50.0 \\
\hline College and above & 0.6 & 0.9 & 2.5 \\
\hline Annual per capita income (US\$) & 352 & 611 & 1165 \\
\hline
\end{tabular}

All parameters changed significantly from 2003 to 2008 and 2013 ( $p<0.001$ ) except for gender composition.

${ }^{*}$ NCMS pilot started in only four provinces in 2003, whereas in 2008 and 2013, NCMS achieved over 95\% coverage in rural China, therefore number enrolled was lower than in 2008 and 2013.

tinpatient service utilisation excludes in-hospital baby delivery.

łincome was CPI-adjusted with reference to 2003; US $\$ 1=¥ 8.2$ in 2003; US $\$ 1=¥ 6.90$ in 2008; US $\$ 1=¥ 6.18$ in 2013.

NCMS, New Cooperative Medical Scheme.

These can also be visualised from the concentration curve (figure 1)

The proportion of households with high medical expenditures were increasing overall and increased more rapidly after 2008. In 2003, 2008 and 2013, 6.7\%, 7.0\% and $8.7 \%$ of sampled households had OOP medical expenditure exceeding $40 \%$ of household income, respectively (table 3). However, subgroup analysis showed that this percentage decreased in the middleincome and high-income quintiles after 2008, and the increase was mostly observed in low-income quintiles (table 3). Consistently, logistic regression models 2 and 3 showed that the increasing trend of medical financial burden was reversed after controlling for households' demographic, socioeconomic characteristics and health needs (table 4 ). When other factors made comparable, the financial burden decreased on a national level from 2003 to 2013. Furthermore, low income, smaller household size, in Western region, with family members over age 60 or have chronic diseases were important contributors to high financial burden (table 4). In model 3, when inpatient service utilisation was added to the model, it was very strongly associated with high financial burden (table 4). Two other indicators of financing burden also showed a reduction in financial barriers over time. The percentage of forgoing necessary admissions (judged by physicians) due to financial difficulties had significantly decreased $(77.5 \%$ in $2003,71.7 \%$ in 2008 and $45.4 \%$ in 2013). The percentage of early hospital discharge due to financial difficulties also significantly decreased from $68.3 \%$ in 2003 to $54.6 \%$ in 2008 and then $37.0 \%$ in 2013 .

\section{Eliminated disparity and improved equity in service utilisation, but widening gap of medical financial burden across income quintiles from 2003 to 2013}

There was significant heterogeneity in outpatient service utilisation across income quintiles and age groups, but over time the disparity related to the 
Table 2 Individuals' utilisation of health services and pattern of inpatient service use in 2003, 2008 and 2013

\begin{tabular}{|c|c|c|c|c|c|c|c|c|c|}
\hline & \multicolumn{3}{|c|}{$\begin{array}{l}\text { Have outpatient visit in the } \\
\text { past } 2 \text { weeks* }(\%)\end{array}$} & \multicolumn{3}{|c|}{$\begin{array}{l}\text { Admission rate within the } \\
\text { past yearf }(\%)\end{array}$} & \multicolumn{3}{|c|}{$\begin{array}{l}\% \text { Admissions in lower level } \\
\text { health facilities } \ddagger\end{array}$} \\
\hline & 2003 & 2008 & 2013 & 2003 & 2008 & 2013 & 2003 & 2008 & 2013 \\
\hline Total & 14.8 & 15.5 & 13.3 & 2.7 & 5.7 & 7.7 & 28.3 & 37.5 & 29.5 \\
\hline \multicolumn{10}{|l|}{ Age group } \\
\hline $0-5$ & 18.1 & 25.0 & 13.8 & 2.9 & 8.3 & 8.4 & 26.7 & 37.6 & 20.2 \\
\hline $6-14$ & 6.3 & 9.1 & 6.2 & 0.7 & 1.9 & 2.3 & 31.3 & 42.3 & 30.1 \\
\hline $15-39$ & 9.4 & 7.6 & 5.3 & 1.7 & 2.9 & 3.0 & 26.7 & 31.8 & 18.4 \\
\hline $40-59$ & 21.1 & 18.2 & 14.9 & 3.5 & 6.5 & 8.1 & 32.0 & 37.7 & 30.9 \\
\hline $60-74$ & 25.5 & 27.5 & 24.2 & 5.7 & 12 & 15.7 & 23.5 & 42.6 & 36.5 \\
\hline $75+$ & 27.6 & 33.6 & 28.0 & 6.9 & 12.7 & 18.2 & 33.3 & 50.4 & 36.6 \\
\hline \multicolumn{10}{|l|}{ Income group } \\
\hline First quintile & 13.5 & 14.7 & 14.5 & 1.8 & 5.2 & 8.6 & 42.9 & 44.3 & 36.1 \\
\hline Second quintile & 14.7 & 16.2 & 13.3 & 2.4 & 5.5 & 7.5 & 34.9 & 40.0 & 28.7 \\
\hline Third quintile & 14.9 & 15.8 & 13.1 & 2.1 & 5.5 & 7.0 & 33.7 & 37.2 & 29.0 \\
\hline Fourth quintile & 15.5 & 14.8 & 12.3 & 2.7 & 5.7 & 7.6 & 25.0 & 35.8 & 27.1 \\
\hline Fifth quintile & 15.2 & 15.9 & 13.2 & 4.1 & 6.4 & 7.8 & 19.1 & 30.5 & 25.8 \\
\hline
\end{tabular}

${ }^{*}$ Rate of outpatient visit in the past 2 weeks defined as total number of outpatient visits in the past 2 weeks over total number of respondents. †Rate of outpatient visit in the past 2 weeks defined as total number of outpatient visits in the past 2 weeks over total number of respondents. łLower level health facilities defined and township health centres and village clinics, higher level health facilities include hospitals at county, city and provincial levels.

income disappeared. Percentage of individuals in the lowest income quintile with outpatient visit in the past 2 weeks increased from $13.5 \%$ in 2003 to $14.5 \%$ in 2013, whereas for all the other quintiles the percentage decreased (table 2). By 2013, the percentage of individuals with outpatient visit was higher in the lowest income quintile. A similar catching up trend was observed on inpatient service utilisation from 2003 to 2013. Hospital admission rates were much higher in the lowest income quintile and elderly. However, individuals in the lowest income quintile still used lower level health facilities (township level and below) more often than those in higher income quintiles.

Analysis on medical financial burden by income quintiles suggests a huge income gap that widened from 2003 to 2013 (table 3). In 2013, 24.7\% of individuals in the lowest-income quintile had catastrophic medical expenditure, compared with $8.5 \%$ in the second income quintile, and $2.5 \%$ in the highest income quintile. From 2003 to 2013, an increasing percentage of households in the lowest income quintile had medical expenditure exceeding $40 \%$ of their household income ( $16.1 \%$ in 2003 and $24.7 \%$ in 2013 ) (table 3 ). On the contrary, the risk of high expenditure was either decreasing or unchanged overtime in the other income quintiles. Logistic regression results also confirm the higher financial burden among the lowestincome quintile even after controlling for other factors (table 4).
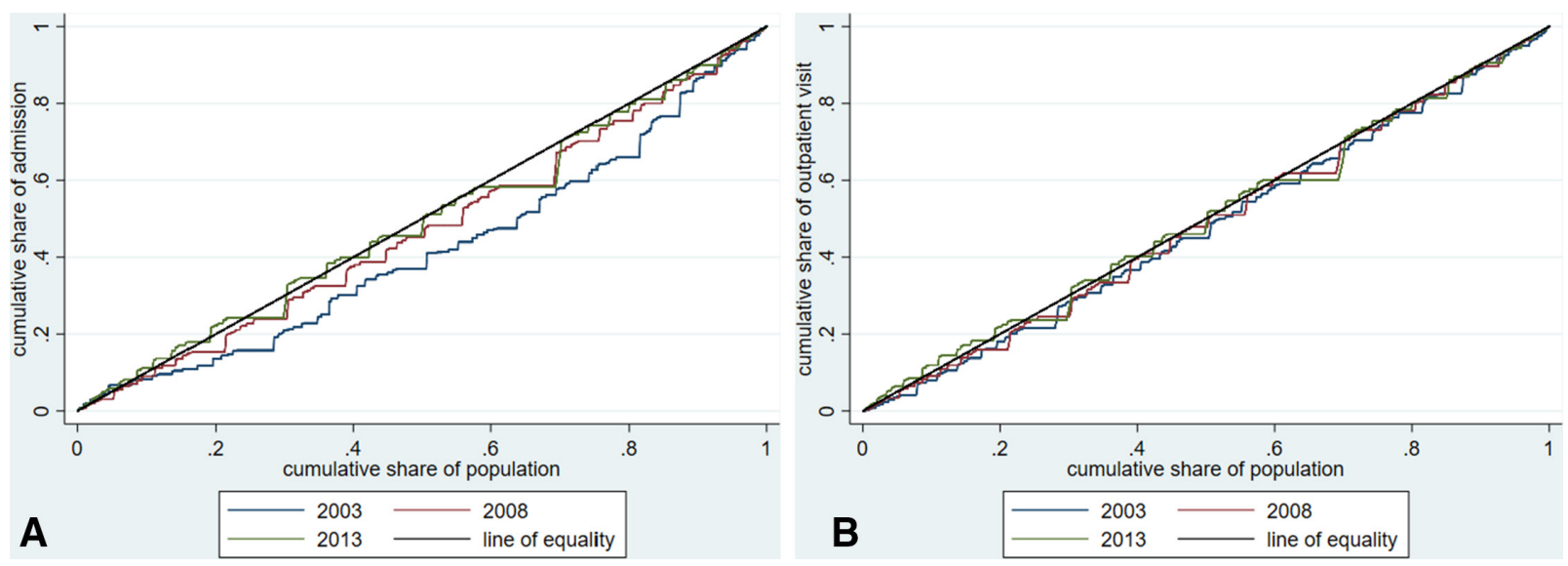

Figure 1 Concentration curve of inpatient admission and outpatient visits with respect to per capita income. 
Table 3 Households' medical financial burden among subgroups in 2003, 2008 and 2013

\begin{tabular}{|c|c|c|c|}
\hline & 2003 & 2008 & 2013 \\
\hline \multicolumn{4}{|l|}{$\%$ of households with health OOP exceeding $40 \%$ of income } \\
\hline Total $(\%)$ & 6.7 & 7.0 & 8.7 \\
\hline \multicolumn{4}{|l|}{ Household size (\%) } \\
\hline $1-2$ persons & 11.7 & 10.7 & 12.7 \\
\hline 3-4 persons & 4.7 & 5.3 & 5.4 \\
\hline Over 5 persons & 5.4 & 4.7 & 5.7 \\
\hline \multicolumn{4}{|l|}{ Highest education of family (\%) } \\
\hline None and primary & 9.7 & 10.8 & 13.4 \\
\hline Secondary & 4.5 & 5.1 & 6.5 \\
\hline College and above & 3.4 & 4.0 & 4.9 \\
\hline \multicolumn{4}{|l|}{ If any member in household over 60 years old (\%) } \\
\hline No member in household over 60 years old & 4.9 & 5.1 & 5.2 \\
\hline At least one member in household over 60 years old & 10.0 & 10.8 & 13.9 \\
\hline \multicolumn{4}{|l|}{ If any member in household below 5 years old (\%) } \\
\hline No member in household below 5 years old & 7.0 & 7.4 & 9.4 \\
\hline At least one member in household below 5 years old & 4.9 & 5.1 & 5.1 \\
\hline \multicolumn{4}{|l|}{ If any member in household has a chronic disease (\%) } \\
\hline No member in household has a chronic disease & 3.1 & 3.5 & 4.3 \\
\hline At least one member in household has a chronic disease & 12.9 & 13.4 & 14.8 \\
\hline \multicolumn{4}{|l|}{ If any member in household used inpatient service recently } \\
\hline No member in household used inpatient service recently & 4.4 & 4.5 & 5.8 \\
\hline At least one member in household used inpatient service recently & 27.8 & 23.5 & 20.3 \\
\hline \multicolumn{4}{|l|}{ Income group } \\
\hline First quintile & 16.1 & 15.4 & 24.7 \\
\hline Second quintile & 8.6 & 8.2 & 8.5 \\
\hline Third quintile & 5.0 & 5.1 & 4.8 \\
\hline Fourth quintile & 3.5 & 4.4 & 4.2 \\
\hline Fifth quintile & 2.5 & 2.7 & 2.5 \\
\hline \multicolumn{4}{|l|}{ Other financial burden measurements at individual levels } \\
\hline Did not get admitted when considered necessary by physicians (\%) & 27.0 & 23.0 & 21.4 \\
\hline Forgone necessary admissions due to financial difficulties (\%) & 77.5 & 71.7 & 45.4 \\
\hline Early discharge due to financial difficulties (\%) & 68.3 & 54.6 & 37.0 \\
\hline
\end{tabular}

OOP, out of pocket.

\section{DISCUSSIONS}

\section{Underlying the national level trends of health service utilisation: two different stages of NCMS reform and healthcare reform in China}

From 2003 to 2008 and 2013, NCMS enrollees' inpatient service utilisation significantly increased; outpatient service utilisation increased from 2003 to 2008 but decreased afterwards. These observations were likely due to the interaction of insurance, demand and supply factors, and need to be interpreted in the context of different stages of NCMS reform and China's healthcare reform.

From 2003 to 2008, the demographic changes were only moderate, but service utilisation had significantly increased. This may be due to the rapid expansion of NCMS coverage and increased supply. From 2003 to 2008, the NCMS rapidly expanded population coverage from less than $10 \%$ to over $90 \%$ of rural population, and mainly covers inpatient services. On the provider side, the number of specialty hospitals and number of large 'general hospitals (those with over 800 beds) increased by fivefold from 2000 to 2008 and the number of beds almost doubled from 2003 to $2013^{17}$. The resulted demand increase may include significant proportion of unmet service demand before NCMS coverage. Our results showed that the rate of forgone necessary admissions decreased from $27 \%$ in 2003 to $23 \%$ in 2008, the proportion of which due to financial difficulties decreased 
Table 4 Factors associated with households having out-of-pocket medical expenditure exceeding $40 \%$ of household income

\begin{tabular}{|c|c|}
\hline & OR (95\% Cl) \\
\hline \multicolumn{2}{|c|}{ Survey year (2003 as base level) } \\
\hline 2008 & $0.70(0.51$ to 0.95$)$ \\
\hline 2013 & $0.65(0.47$ to 0.90$)$ \\
\hline \multicolumn{2}{|c|}{ Area (west is base level) } \\
\hline East & 0.79 (0.57 to 1.10$)$ \\
\hline Central & $0.71(0.48$ to 1.05$)$ \\
\hline \multicolumn{2}{|c|}{ Income group (first quintile is base level) } \\
\hline Second quintile & $0.32(0.27$ to 0.37$)$ \\
\hline Third quintile & $0.19(0.16$ to 0.23$)$ \\
\hline Fourth quintile & $0.14(0.12$ to 0.17$)$ \\
\hline Fifth quintile & 0.08 (0.06 to 0.09$)$ \\
\hline \multicolumn{2}{|c|}{ Household size (1-2 person as base level) } \\
\hline $3-4$ persons & $0.43(0.40$ to 0.47$)$ \\
\hline Over 5 persons & $0.22(0.18$ to 0.27$)$ \\
\hline \multicolumn{2}{|c|}{$\begin{array}{l}\text { If any member in household is below } 5 \text { years old (no is base } \\
\text { level) }\end{array}$} \\
\hline Yes & $1.00(0.89$ to 1.11$)$ \\
\hline \multicolumn{2}{|c|}{$\begin{array}{l}\text { If any member in household is over } 60 \text { years old (no is base } \\
\text { level) }\end{array}$} \\
\hline Yes & 1.07 (0.97 to 1.18$)$ \\
\hline \multicolumn{2}{|c|}{$\begin{array}{l}\text { If any member in household has a chronic disease (no is } \\
\text { base level) }\end{array}$} \\
\hline Yes & 2.65 (2.38 to 2.95$)$ \\
\hline \multicolumn{2}{|c|}{$\begin{array}{l}\text { If any member in household used inpatient service (no is } \\
\text { base level) }\end{array}$} \\
\hline Yes & 5.45 (4.77 to 6.22$)$ \\
\hline
\end{tabular}

Please refer to online supplemental table 2 for a comparison of models.

from $77.5 \%$ to $45.4 \%$ over the same period. However, the NCMS premium only slightly increased from $¥ 30$ (US\$4.6) to ¥96 (US\$13.9), and therefore, NCMS can only afford relatively low reimbursement rates and caps. As a result, increased percentage of services were used at the lower level health facilities that were less costly.

From 2008 to 2013, NCMS significantly increased premium to $¥ 370$ (US\$59) in 2013 and expanded its benefit package. The new healthcare reform in 2009 also introduced $¥ 850$ billion (US $\$ 123$ billion) investment from government over 3 years (2009-2011) in health systems, with around $46 \%$ flowing into public health insurance programs. ${ }^{15}$ In 2010, many cities and counties started to cover outpatient services in their local NCMS policies. In the same year, 22 catastrophic diseases were set eligible for higher reimbursement rate under NCMS. On the demand side, ageing and increasing prevalence of chronic diseases, together with income growth, lead to higher demand for medical services. Both effects lead to increase in service utilisation, and more utilisation in higher level health facilities.

\section{Interpreting the financial risk protection by NCMS}

Most studies conducted before 2010 did not find positive impact of NCMS on financial risk protection, ${ }^{2-4} 7111415$ likely due to the low NCMS premium level and limited risk protection effects before 2008. With more recent data, larger sample size and detailed subgroup analyses, our study identified a positive financial risk protection effect of NCMS. Though on a national level, the proportion of households spending over $40 \%$ of income on medical care increased from 2003 to 2013, the increase was only seen in the two low-income quintiles, and a decrease was observed in the middle-income and high-income quintiles after 2008. A closer examination of determinants reveals that the increase was correlated to population ageing, and the higher prevalence of chronic diseases, which was more commonly observed in recent years. In addition, coverage expansion to households in the West region, with smaller household size, with lower education levels, and low incomes were more likely to result in high financial burden due to their lower ability to pay. After controlling for these contributing factors to make financial burden comparable across different years, the likelihood of having high financial burden was lower in 2013 compared with 2003, implying the positive effect of NCMS in reducing financial burden over the last decade.

Even in the group with increased financial burden, it is controversial if higher share of medical expenditure is necessarily detrimental. Expenditure needs to be evaluated together with service utilisation and health outcome. Elevated expenditure could reflect the willingness to pay for health services that were previously inaccessible or unaffordable. In addition, there is a methodological issue with financial burden measures in China. Chinese households usually have significant amount savings. Therefore, annual income significantly underestimates wealth, and it is difficult to identify a threshold that truly defines 'catastrophic' expenditure.

\section{Interpreting the equity impact of NCMS}

Improving health service access for the poor and improve equity is an important goal of NCMS. Our study shows that in 2003, there was a clear income gradient of outpatient visit rate and admission rate, with higher rate of utilisation among higher income quintiles. However, in 2013, the gap in quantity of service utilisation had disappeared, and the trend was reversed. Individuals from the lowest-income quintile even used more services than other groups, likely due to their poorer health status and better affordability of health services due to increased coverage by NCMS. The concentration curve showed a clear improvement in equity of inpatient service access gradually from 2003 to 2008, then 2013. By 2013, there was no significant correlation between income level and likelihood of hospital admissions. Nevertheless, lowerincome individuals were still more likely to receive 
treatment in lower-level health facilities, indicating the disparity in quality of services received.

Households from the lowest-income quintile were much more likely to have high financial burden and was the only group with significantly increasing financial burden from 2003 to 2013. This group also had poorer health, and it is likely that diseases further induce poverty. Our results suggest that the current level of NCMS financial protection to the low-income groups are not sufficient, and this group should be the key target for future health insurance reforms in order to further reduce disparity in financial risk protection and health services access. Reducing financial burden among the low-income may require a synergic effort between NCMS reimbursement and the Medical Financial Assistance of the Ministry of Civil Affairs that offers additional subsidy on OOP expenditures and living assistance for the poor and elderly.

\section{Towards UHC: lessons for other middle-income and low- income countries}

WHO's UHC cube conceptualised the three dimensions a country needs to consider when developing UHCpopulation coverage, service package and financial protection from direct costs. With limited resource in middle-income and low-income countries, trade-offs often need to be made among the three dimensions. Nevertheless, it is unclear what dimension countries should prioritise at different stages towards UHC, as countries embark on different paths. Rural residents are the most challenging population for UHC due to lower income, worse health status, and poorer access to health services. China established a separate insurance scheme for the rural population and took a stepwise approach in achieving the competing priorities, which offers a roadmap for countries in the early stages of UHC for rural population. At the beginning of NCMS rolling out, policy was focused on rapidly increasing population coverage with relatively low service coverage and low reimbursement rate. The relatively low premium, and high proportion of government subsidy reduced barriers of enrolment. To encourage enrolment, the reimbursement list was extensive and covered both inpatient and outpatient care so that many enrollees would be eligible for reimbursement, despite the low reimbursement level. Furthermore, village doctors and community leaders also played an active role conducting public campaign and education to encourage households' enrolment. Consequently, the big risk pool with relatively low selfselection laid the good foundation for the next stage of reform. Without establishing a large risk pool, social health insurance programs can quickly run into sustanability problems, as seen in many countries. In the second stage, premium and individual contribution were significantly increased, which allows higher reimbursement and improved financial protection. To protect enrollees against catastrophic expenditure, NCMS disproportionally increased the coverage for major diseases associated with high expenditure. To reduce financial burden of enrolling in NCMS, government investment grew proportional to the premium growth, with additional premium subsidy provided to low-income population. Recently, the benefit package and reimbursement level for rural residents are close to that for the urban residents, leading NCMS reform to the third stage of integration with the URBMI scheme. To improve the equity between urban and rural, URBMI and NCMS was announced to be integrated into URRBMI by 2018, following the same policy framework of NCMS in financial contribution and benefit package. In 2018, over $90 \%$ of the provinces have completed the integration of NCMS and URBMI into URRBMI, which is likely to enlarge the risk pool and further reduce urban-rural disparity. Importantly, along with all stages of health insurance coverage expansion, supply side capacity needs to be strengthened at the same time. At all stages of NCMS reform, particularly in the second stage since 2019, the service provision system was significantly expanded to supply more health services and medicines, which ensures the improvement in service access.

\section{Limitations}

The study is not without limitations. First, as with all selfreported data, some variables used in the analysis might be subject to measurement errors. Income tends to be systematically under-reported, which may lead to overestimation of financial burden. Yet the trends in financial burden should not be affected. Second, NCMS reimbursement policies are developed and implemented at various levels in different provinces. There is heterogeneity in actual NCMS reimbursements as well as changes in NCMS policies across regions, which may not be fully controlled by the model. Third, the study would not distinguish between appropriate utilisation of outpatient services and induced unnecessary care, therefore, quality of outpatient care can only be inferred from health and location of care. For inpatient care, the study was unable to identify necessary utilisations. Fourth, as a correlational study that focused on the trends, the statistical analyses in the study could not establish causal relationships. Fifth, the study did not consider life style factors and changes over time which could have direct and indirect impacts on service utilisation. Lastly, there was no control group and data in 2018 has not been used for two reasons: NCMS in majority of the provinces of China was merged with URBMI after 2018 into URRBMI. Therefore, adding the data from the 2018 survey will not help achieve our study objectives; second, there were three major health insurance schemes in China during our study period and the beneficiaries of the three schemes varied in demographics and socioeconomic characters. It may not be appropriate to undertake robust comparisons. However, current setting of our study is still able to observe the impact of changing NCMS policies on service use, financial protection and equity. 


\section{CONCLUSIONS}

From the launch of NCMS in 2003 to 2013, rural Chinese residents enrolled in NCMS had increased inpatient and outpatient service utilisations. The disparity in service utilisation with respect to income had been largely reduced and equity in service utilisation was significantly improved. The study found that NCMS had strong positive effects in financial risk protection. After 2008, fewer middle-income and high-income rural households had catastrophic medical expenditures, however, financial burden in low-income households increased over the years, partially due to the poorer health. The low-income rural residents had high disease burden and financial risk, therefore, should be the priority target of future health insurance reforms. The evolvement of NCMS in China provides a feasible road map towards UHC for other middle-income and low-income countries.

\section{Author affiliations}

${ }^{1}$ Center for Health Statistics and Information, National Health Commission of Peoples Republic of China, Beijing, China

${ }^{2}$ Global Health Research Center, Duke Kunshan University, Kunshan, China ${ }^{3}$ Health Human Resources Development Center, National Health Commission of Peoples Republic of China, Beijing, China

${ }^{4}$ Duke Global Health Institute, Duke University, Durham, North Carolina, USA

${ }^{5}$ Department of Economics, Duke University, Durham, North Carolina, USA

Contributors YZ, DD, WM, ZM, ST and FS contributed to study design. YZ, LX and ZM conducted data collection. YZ, DD and WM conducted data analysis. DD, WM, YZ, ST and and FS drafted the manuscript.

Funding This work was supported by Duke Kunshan University internal research grant, and Duke University internal research grant.

\section{Competing interests None declared.}

\section{Patient consent for publication Not required.}

Provenance and peer review Not commissioned; externally peer reviewed.

Data availability statement Raw Data are with the China National Health Commission Statistical Information Center, and are not publicly available.

Supplemental material This content has been supplied by the author(s). It has not been vetted by BMJ Publishing Group Limited (BMJ) and may not have been peer-reviewed. Any opinions or recommendations discussed are solely those of the author(s) and are not endorsed by BMJ. BMJ disclaims all liability and responsibility arising from any reliance placed on the content. Where the content includes any translated material, BMJ does not warrant the accuracy and reliability of the translations (including but not limited to local regulations, clinical guidelines, terminology, drug names and drug dosages), and is not responsible for any error and/or omissions arising from translation and adaptation or otherwise.

Open access This is an open access article distributed in accordance with the Creative Commons Attribution Non Commercial (CC BY-NC 4.0) license, which permits others to distribute, remix, adapt, build upon this work non-commercially, and license their derivative works on different terms, provided the original work is properly cited, appropriate credit is given, any changes made indicated, and the use is non-commercial. See: http://creativecommons.org/licenses/by-nc/4.0/.

\section{ORCID iDs}

Di Dong http://orcid.org/0000-0002-5425-444X

Wenhui Mao http://orcid.org/0000-0001-9214-7787

\section{REFERENCES}

1 National Bureau of Statistics of China. Annual Data-Conditions of new cooperative medical scheme. Available: http://data.stats.gov. cn/english/easyquery.htm?cn=C01 [Accessed 21 Feb 2017].

2 Hu S, Tang S, Liu Y, et al. Reform of how health care is paid for in China: challenges and opportunities. Lancet 2008;372:1846-53.

3 Wagstaff A, Lindelow M, Jun G, et al. Extending health insurance to the rural population: an impact evaluation of China's new cooperative medical scheme. J Health Econ 2009;28:1-19.

4 Wagstaff A, Lindelow M. Can insurance increase financial risk? The curious case of health insurance in China. J Health Econ 2008;27:990-1005.

5 State Council of China. 2010 work plan for 5 key initiatives of health care reform., 2010. Available: http://www.nhfpc.gov.cn/zwgk/wtwj/ 201304/6eccf48010034618aedb147555274638.shtml [Accessed 21 Feb 2017].

6 National Health and Family Planning Commission of China. Progress of NCMS in 2013 and work priority in 2014. Available: http://www. nhfpc.gov.cn/zhuz/xwfb/201405/6e9c1e197f0242b1b47647a3 48f22035.shtml [Accessed 21 Feb 2017].

7 Lei X, Lin W. The new cooperative medical scheme in rural China: does more coverage mean more service and better health? Health Econ 2009;18 Suppl 2:S25-46.

8 Wagstaff A, Yip W, Lindelow M, et al. China's health system and its reform: a review of recent studies. Health Econ 2009;18 Suppl 2:S7-23.

9 Yu B, Meng Q, Collins C, et al. How does the new cooperative medical scheme influence health service utilization? A study in two provinces in rural China. BMC Health Serv Res 2010;10:116.

10 Liu X, Tang S, Yu B, et al. Can rural health insurance improve equity in health care utilization? A comparison between China and Vietnam. Int J Equity Health 2012;11:10.

11 Cheng L, Liu H, Zhang Y, et al. The impact of health insurance on health outcomes and spending of the elderly: evidence from China's new cooperative medical scheme. Health Econ 2015;24:672-91.

12 Liu X, Sun X, Zhao Y, et al. Financial protection of rural health insurance for patients with hypertension and diabetes: repeated cross-sectional surveys in rural China. BMC Health Serv Res 2016;16:481.

13 Dai T, Hu H-P, Na X, et al. Effects of new rural cooperative medical scheme on medical service utilization and medical expense control of inpatients: a 3-year empirical study of Hainan Province in China. Chin Med J 2016;129:1280-4.

14 Sun Q, Liu X, Meng Q, et al. Evaluating the financial protection of patients with chronic disease by health insurance in rural China. Int J Equity Health 2009;8:42.

15 Babiarz KS, Miller G, Yi H, et al. New evidence on the impact of China's new rural cooperative medical scheme and its implications for rural primary healthcare: multivariate difference-in-difference analysis. BMJ 2010;341:c5617.

16 Yip W, Hsiao WC. Non-evidence-based policy: how effective is China's new cooperative medical scheme in reducing medical impoverishment? Soc Sci Med 2009;68:201-9.

17 Ministry of Health. China Health Statistical yearbook. Beijing: Peking Union Medical College, 2008. 